\title{
Learning Preferences and Experiences in Different Environments
}

\author{
Joseph Lee \\ Faculty of Business, Communication and Law, INTI International University, Malaysia
}

Copyright $\mathrm{C} 2019$ by authors, all rights reserved. Authors agree that this article remains permanently open access under the terms of the Creative Commons Attribution License 4.0 International License

\begin{abstract}
Everyone learns, but not all learn in the same way. Understanding of learning styles theory offers opportunities to manage the learning process better and knowing an individual's learning styles is also useful in formulating effective teaching strategy. Many investigated and reviewed the impacts of gender, cultural differences, and variations on disciplines to learning style. This study compares the impacts of learning experiences on learning style between students with similar backgrounds at different studying locations. Data were collected from questionnaires for the Index of Learning Style (ILS) that has been developed by Felder-Solomon. A total of 841 students are included in this study comprising students from Malaysia and China. The findings indicate that changes in students' learning style preferences are conceivable as they gain different learning experiences at a different studying location.
\end{abstract}

Keywords Learning Styles, Learning Preferences, Learning Experiences

\section{Introduction}

Everyone learns, but not all people learn in the same way. Although assessing students' learning preferences can be time-consuming and at times difficult, understanding of an individual's natural or habitual pattern of processing information, acquiring knowledge and solving problems is generally accepted as beneficial.

Learning styles have been described as: "the view that different people learn information in different ways" (Pashler et al., 2009). Over the years, a number of different learning styles theories have emerged including Kolb (1984) and Felder and Silverman (1988). While Pashler et al. (2009) believe the popularity of the learning-styles approach may be due to its success in fostering learning and instruction, theory and practice of learning styles has generated both great interest and controversy (Coffield et al., 2004).

Kazu (2009) contemplates confidence in learning will consistently rise when learners know how to learn. Learning to learn and grasping knowledge in a suitable manner will lessen the need for an overbearing control by teachers. Likewise, Ahmad \& Anuar (2016) believe understanding learning styles is important to the students and have to be prioritized by all teachers in the learning process in the classroom. However, Kirschner \& van Merriënboer (2013) argue the preferred way of learning does not need to be the most productive way of learning.

Nevertheless, attention to learning styles theory has offered opportunities to better manage the learning process and knowing an individual's learning style is also useful in formulating effective teaching strategy.

While many researchers have investigated and reviewed the impacts of gender, cultural differences, and variations in disciplines on learning styles, the objective of this study is to understand whether there are any learning style differences of students with similar backgrounds at different studying locations or learning environments.

\section{Learning Styles}

There are an abundance of theories, assessment tools and methodologies about learning styles. Based on the theory of experiential learning, Kolb's Learning Style Model assesses how individuals receive and interpret information, and how they learn through experiences (Kolb, 1984). It differentiates concrete experience (CE), abstract conceptualization (AC), reflective observation (RO) and active experimentation (AE) learning abilities.

With the aim of capturing the most important learning style differences and providing a good basis to formulate a teaching approach that would address the learning needs of all students, the Felder-Silverman Learning Styles Inventory describes five dichotomous learning style dimensions which indicate the students' preferences, namely 
- How is the information processed: actively-through physical activity or discussion, or reflectively—-through introspection?

- What type of information is preferentially perceived: sensory - sights, or intuitive - memories?

- Through which modality is sensory information most effectively perceived: visual—pictures, or verbal — written and spoken words?

- How is understanding progressed: sequentially-in logical steps, or globally - in large jumps, holistically?

- With which organization of information is the most comfortable for the student: inductive - facts and observations, or deductive-principles are given, consequences and applications are deduced?

The last named dimension is not assessed in the Index of Learning Styles (ILS) because as Felder states it “...the "best" method of teaching is inductive, whether it be called problem-based learning, discovery learning, inquiry learning, or some variation on the same theme."(Felder, 2012)

\section{Method}

Considering the diverse cultural backgrounds of the intended sample of this study, the Felder-Silverman ILS is adopted as participants who are expected to be more responsive to the simple language and short questions. In addition, it is easier to make references and draw comparisons based on the numerical values of the various styles.

The questionnaire for this study consists of two sections. Section A requires participants to fill out their demographic details and Section B is to assess learning preferences that reflect the psychological and behavioral characteristics of four dimensions as described and defined in the original work by Felder and Silverman (1988).

Students' responses to the Index of Learning Styles (ILS) survey were collected either via online or hardcopy questionnaire distributed. The mean and standard deviation of each ILS scale were computed to determine the students' preferences of learning styles.

While a larger sample dataset was obtained from randomly selected groups of students in academic institutes that can be reached in various countries, a subset is identified based on the place of origin for further analysis to evaluate any learning style differences of students with similar backgrounds at different studying locations.

A total of 841 students are included in this study comprising 487 (57.91\%) female and 354 (42.09\%) male students. About $75.39 \%$ of the students are from Malaysia, and $24.61 \%$ are from China. Among the samples, 41 students from China are currently studying in Malaysia while 166 study in China. This is illustrated in the following table.
Table 1. Profile of Participants

\begin{tabular}{|c|c|c|}
\hline & Frequency & Percentage \\
\hline Gender & & \\
\hline Male & 354 & $42.09 \%$ \\
\hline Female & 487 & $57.91 \%$ \\
\hline Please of Origin & & \\
\hline Malaysia & 634 & $75.39 \%$ \\
\hline China & 207 & $24.61 \%$ \\
\hline Location of Study & & $80.26 \%$ \\
\hline Malaysia & 675 & $19.74 \%$ \\
\hline China & 166 & \\
\hline
\end{tabular}

\section{Findings and Discussion}

The Felder-Silverman ILS learning styles dimensions are dichotomous, consisting of 11 forced-choice items for each domain with scores ranging from -11 to +11 in increments of 2. These dimensions represent continua rather than either/or categories and scoring indicates preferences may be strong (9-11), moderate (5-7) or balanced (1-3).

Figure 1 presents descriptive statistics for each of the four Felder-Silverman learning style dimensions.

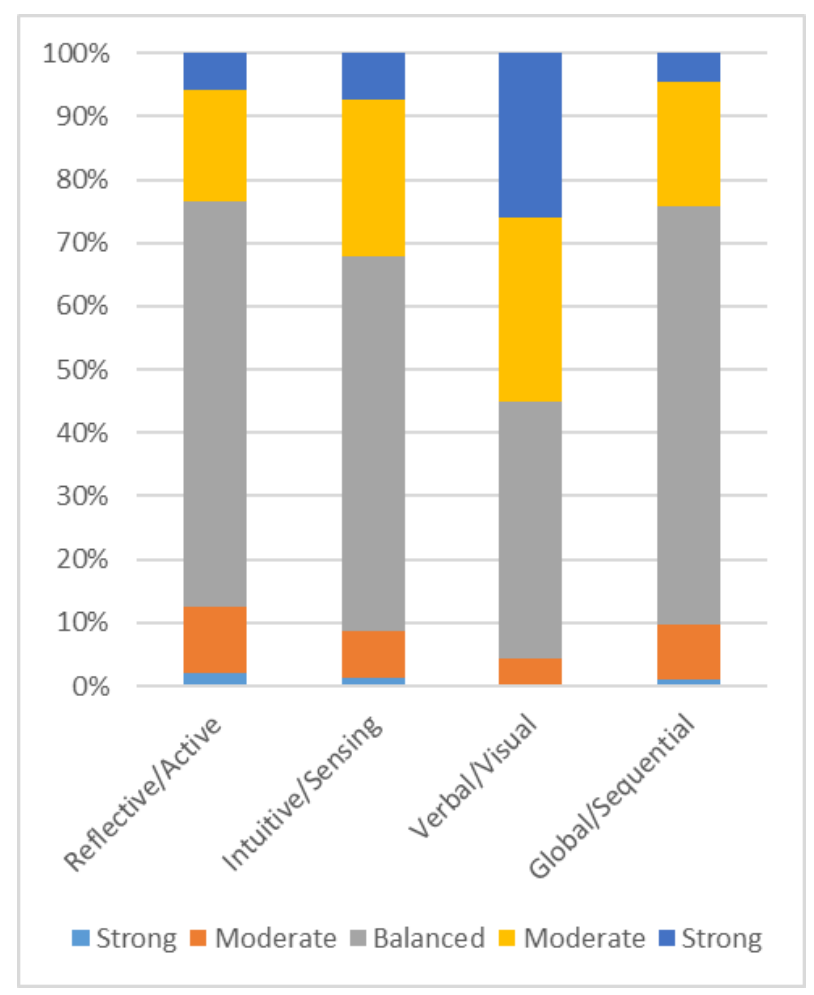

Figure 1. Overall Pattern

The overall pattern of the learning preferences resembles findings of Moussa (2018), Lowdermilk et al. (2017), Nor Asiah et al. (2015) and Dcruz, Rajaratnam \& Chandrasekhar (2013) and are largely consistent with Tee 
et al. (2015) with the following observations.

- On the active-reflective dimension the majority of students $(64.92 \%)$ are balanced. When combined with students who scored active on the continuum, $87.16 \%$ score either active or balanced.

- On the sensing-intuitive dimension a small percentage $(8.92 \%)$ of students are intuitive. When combined with students who were balanced, $90.96 \%$ are either sensing or balanced.

- On the visual-verbal dimension, half of the students $(55.4 \%)$ are visual with a small percentage $(4.52 \%)$ are verbal.

- On the sequential-global dimension the majority of students (66.94\%) are balanced. When combined with students who were sequential, $90.25 \%$ are either sequential or balanced with less than $10 \%$ of students are global.
Figure 2 further illustrates whether different learning experiences of students from the same place of origin (i.e. China) study at different locations (that is, Malaysia and China) may have an impact on their learning preferences.

Although not subjected to statistical testing, descriptive statistics of Tables 2 - 5 compare students' learning style preferences of the four learning style dimensions as they gain different learning experiences at different studying locations.

These findings indicate there are variations, which are consistent with the findings of Csapo \& Hayen (2006) that changes of learning style preferences are conceivable when progressing through their education.

Also, the variations observed in this study appear to be comparable with Bitran et al. (2012) in a cross-sectional comparison of learning style preferences of undergraduate medical students of different levels and in the longitudinal follow-up study of these students.

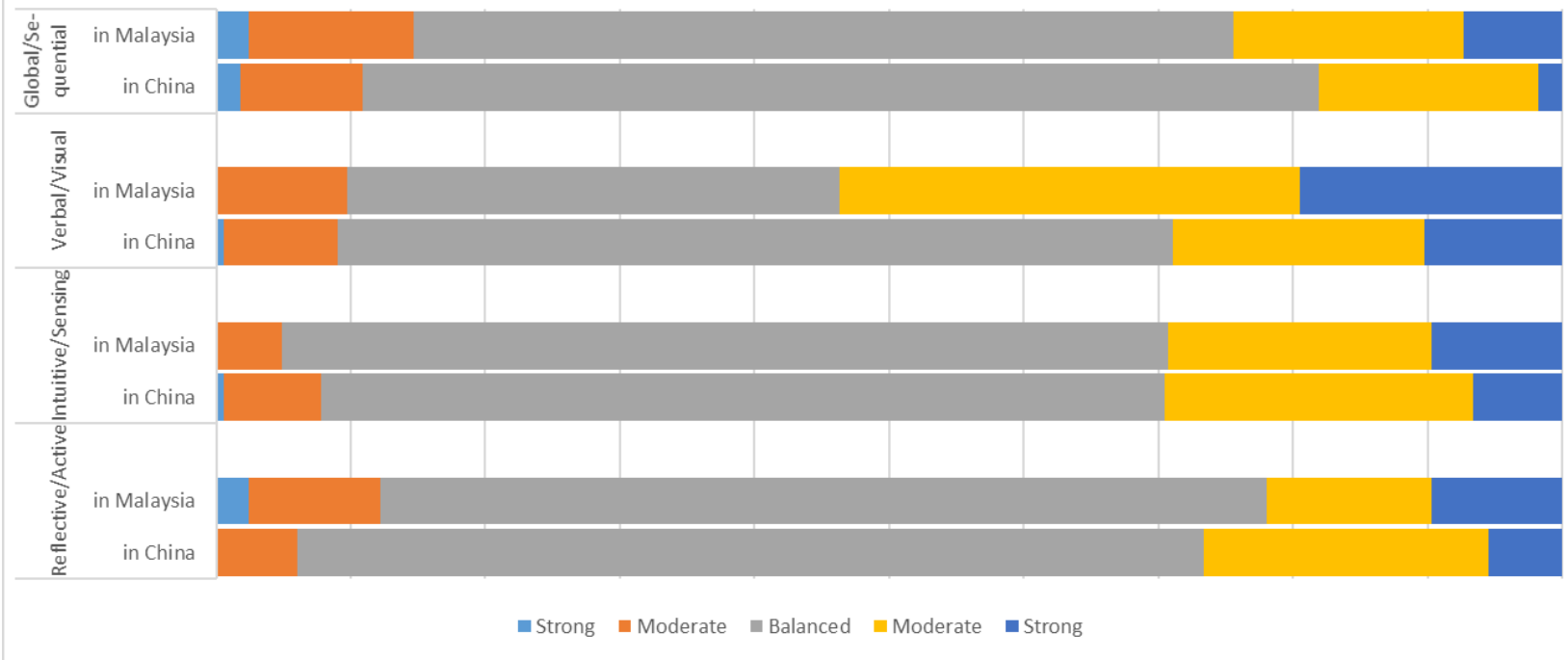

Figure 2. Learning Style Preferences at Different Locations

Table 2. Active-Reflective Dimension

\begin{tabular}{|c|c|c|c|c|c|c|}
\hline & \multicolumn{3}{|c|}{ Reflective } & \multicolumn{3}{c|}{ Active } \\
\hline & Strong & Moderate & Balanced & Balanced & Moderate & Strong \\
\hline & $(-11$ to -9$)$ & $(-7$ to -5$)$ & $(-3$ to -1$)$ & $(1-3)$ & $(5-7)$ & $(9$ to 11$)$ \\
\hline China & $0.00 \%$ & $6.02 \%$ & $28.31 \%$ & $38.55 \%$ & $21.08 \%$ & $5.42 \%$ \\
\hline Malaysia & $2.44 \%$ & $9.76 \%$ & $14.63 \%$ & $51.22 \%$ & $12.20 \%$ & $9.76 \%$ \\
\hline
\end{tabular}

Table 3. Sensing-Intuitive Dimension

\begin{tabular}{|c|c|c|c|c|c|c|}
\hline & \multicolumn{3}{|c|}{ Intuitive } & \multicolumn{3}{c|}{ Sensing } \\
\hline & Strong & Moderate & Balanced & Balanced & Moderate & Strong \\
\hline & $(-11$ to -9$)$ & $(-7$ to -5$)$ & $(-3$ to -1$)$ & $(1-3)$ & $(5-7)$ & $(9$ to 11$)$ \\
\hline China & $0.60 \%$ & $7.23 \%$ & $30.72 \%$ & $31.93 \%$ & $22.89 \%$ & $6.63 \%$ \\
\hline Malaysia & $0.00 \%$ & $4.88 \%$ & $19.51 \%$ & $46.34 \%$ & $19.51 \%$ & $9.76 \%$ \\
\hline
\end{tabular}


Table 4. Visual-Verbal Dimension

\begin{tabular}{|c|c|c|c|c|c|c|}
\hline & \multicolumn{3}{|c|}{ Verbal } & \multicolumn{3}{c|}{ Visual } \\
\hline & Strong & Moderate & Balanced & Balanced & Moderate & Strong \\
\hline & $(-11$ to -9$)$ & $(-7$ to -5$)$ & $(-3$ to -1$)$ & $(1-3)$ & $(5-7)$ & $(9$ to 11$)$ \\
\hline China & $0.60 \%$ & $8.43 \%$ & $21.69 \%$ & $40.36 \%$ & $18.67 \%$ & $10.24 \%$ \\
\hline Malaysia & $0.00 \%$ & $9.76 \%$ & $7.32 \%$ & $29.27 \%$ & $34.15 \%$ & $19.51 \%$ \\
\hline
\end{tabular}

Table 5. Sequential-Global Dimension

\begin{tabular}{|c|c|c|c|c|c|c|}
\hline & \multicolumn{3}{|c|}{ Global } & \multicolumn{3}{c|}{ Sequential } \\
\hline & Strong & Moderate & Balanced & Balanced & Moderate & Strong \\
\hline & $(-11$ to -9$)$ & $(-7$ to -5$)$ & $(-3$ to -1$)$ & $(1-3)$ & $(5-7)$ & $(9$ to 11$)$ \\
\hline China & $1.81 \%$ & $9.04 \%$ & $36.14 \%$ & $34.94 \%$ & $16.27 \%$ & $1.81 \%$ \\
\hline Malaysia & $2.44 \%$ & $12.20 \%$ & $31.71 \%$ & $29.27 \%$ & $17.07 \%$ & $7.32 \%$ \\
\hline
\end{tabular}

These findings also support the views of Platsidou \& Metallidou (2009) that learning styles should be considered as a useful tool for supporting communication between student and teacher, encouraging the student to reflect on his/her own learning experience and actively seek different ways in which it can be improved. Similarly, as suggested by El-Hmoudova (2014), each learning style is special but they have both strengths and weaknesses, which means that assistance to students in adjusting and working in styles that may not be the most comfortable for them is essential.

\section{Conclusions}

This study aims to explore if there is a relationship between studying locations and learning style differences of students with similar backgrounds. The findings suggest that changes in learning preferences are conceivable which may contribute to different teaching approaches, learning experiences and assessment strategies.

With the observation in mind, it is important to note that while there may be differences in how certain types of information are being processed, the awareness and knowledge of learning styles are beneficial for both students and teachers. In addition, students do not necessarily have to use all of the learning styles but rather to choose what is better and feasible to be used in the classroom of different learning environments and all should know students with any learning style preferences have the equal opportunities of being successful with all efforts.

Furthermore, considering the increasing importance of internationalization of education and rapid expansion of international student exchanges, further longitudinal study with a homogenous group of students who have experiences in studying in different countries is recommended for better insights into the dynamics of learning styles preferences in different learning situations and contexts.

\section{Acknowledgements}

This research is curiosity-driven. It is part of INTI International University funded research project led by Dr R. Sagadavan. Gracious gratitude to Dr. R. Sagadavan and her team for sharing the raw data.

\section{REFERENCES}

[1] Ahmad S. J. \& Anuar A. (2016). The Relationship between Learning Style and Student Achievement In History Subject. International Journal of Humanities and Social Science. 21(7), p7-14.

[2] Bitran, M., Zúñiga, D., Pedrals, N., Padilla, O., \& Mena, B. (2012). Medical Students' Change in Learning Styles during the Course of the Undergraduate Program: From 'Thinking and Watching' to 'Thinking and Doing'. Canadian Medical Education Journal, 3(2), p86-97.

[3] Csapo, N. \& Hayen, R. (2006). The Role of Learning Styles in the Teaching/Learning Process. Issues in Information Systems 7(1), p129-133.

[4] Coffield, F., Moseley, D., Hall, E. \& Ecclestone, K. (2004). Learning Styles and Pedagogy in Post-16 Learning: A Systematic and Critical Review. London: Learning and Skills research Centre.

[5] Dcruz, S., Rajaratnam, N. \& Chandrasekhar, M. (2013). Learning Styles of First Year Medical Students Studying Physiology in Tamil Nadu. International Journal of Medical Research \& Health Sciences. 2(3), p321-327.

[6] El-Hmoudova, D. (2014). Assessment of Individual Learning Style Preferences With Respect To the Key Language Competences. Procedia-Social and Behavioral Sciences. 171, p40-48.

[7] Felder, R. M. \& Silverman, L. K. (1988). Learning and 
Teaching Styles in Engineering Education. Engineering Education 78(7), p674-681.

[8] Felder, R. M. \& Soloman, B. A. Index of Learning Styles Questionnaire.

[9] Kazu, I.Y. (2009). The Effect of Learning Styles on Education and the Teaching Process. Journal of Social Sciences 5(2), p85-94.

[10] Kirschner, P. \& van Merriënboer J (2013) Do learners really know best? Urban legends in education. Educational Psychologist. 48(3), p169-183.

[11] Lowdermilk, M., lampley, J.; Tweed, S.; \& Lampley, S. A. (2017). Learning Styles of Physical Therapy and Physical Therapy Assistant Students in Accredited Physical Therapy Programs. Journal of Learning in Higher Education. 13(2), p59-65.

[12] Moussa, N. (2018). Learning Styles and the Adoption of Modern Technology among Adult Learners. Institute for Learning Styles Journal, v1, p11-21.

[13] Nor Asiah, Ab G., Nik Rozina@Nik Azyyati. N. J. \& Nik Suriani N. F. (2015). Learning Styles of Business Students at a Malaysian Polytechnic, International Journal of Education and Research, 3(10), p275 - 288.

[14] Pashler, H. McDaniel, M. \& Rohrer D. et al. (2009) Learning styles: Concepts and evidence. Psychological Science in the Public Interest 9, p105-119.

[15] Platsidou, M. \& Metallidou, P. (2009). Validity and Reliability Issues of Two Learning Style Inventories in a Greek Sample: Kolb's Learning Style Inventory and Felder \& Soloman's Index of Learning Styles. International Journal of Teaching and Learning in Higher Education. 20, p324-335.

[16] Tee, T., Yunos, J., Kuppusamy, B., Yee, M. H., Mimi, M. M., Othman, W. Che Rus, R. \& Hanapi, Z. (2015). The Pattern of Learning Styles among Second Year Students in Business Management and Hospitality Programs at One of the Vocational College in Northern Zone. Procedia - Social and Behavioral Sciences 204, p62-72.

[17] Bitran, M., Zúñiga, D., Pedrals, N., Padilla, O., \& Mena, B. (2012). Medical Students' Change in Learning Styles during the Course of the Undergraduate Program: From 'Thinking and Watching' to 'Thinking and Doing'. Canadian Medical Education Journal, 3(2), p86-97 